\title{
Distribution of the CCR2-64I allele in three Brazilian ethnic groups
}

\author{
Angelina Xavier Acosta ${ }^{1,3}$, Rogério Grimaldi Sampaio ${ }^{1,2}$, Juliana Lima Spínola ${ }^{1}$ \\ and Bernardo Galvão-Castro ${ }^{1,2}$ \\ ${ }^{1}$ Laboratório Avançado de Saúde Pública, Centro de Pesquisas Gonçalo Moniz/FIOCRUZ, \\ Salvador-BA, Brazil. \\ ${ }^{2}$ Escola Bahiana de Medicina e Saúde Pública/Fundação para o Desenvolvimento das Ciências, \\ Salvador-BA, Brazil. \\ ${ }^{3}$ Universidade Federal da Bahia, Faculdade de Medicina, Departamento de Pediatria, Salvador-BA, Brazil.
}

\begin{abstract}
CCR2 is a member of the superfamily of seven transmembrane domain G protein-coupled receptors, the largest receptor superfamily in the human genome. CCR2 acts as a receptor for MCP-1 (CC chemokine) and as a co-receptor for HIV-1 cell-target entry. The gene encoding this receptor is mapped to the chromosome band 3p21. A G-to-A transition at position 190 characterizes the CCR2-64I mutation, causing valine to isoleucine substitution in codon 64. This mutation has been identified as an important factor for delaying progression to AIDS. Here, we determined the prevalence of this allele in three different Brazilian populations: 261 Amerindians inhabiting an isolated region in northern Brazil (82 samples from the Waiampi tribe, and 179 samples from the Tiriyó tribe); 89 German descendents from Joinville, a city in southern Brazil; and 305 individuals of predominantly African ancestry, from Salvador, a city in northeast Brazil. The CCR2-64I mutant allele was identified in $26 \%$ of the Tiryió and $30 \%$ of Waiampi samples, in $18 \%$ of the Joinville samples, and in $14 \%$ of the Salvador samples.
\end{abstract}

Key words: CCR2-64I mutation, Brazilian populations, HIV co-receptor.

Received: December 9, 2002; Accepted: May 18, 2003.

\section{Introduction}

Chemokine and chemotaxis cytokine-activated receptors from the superfamily of seven transmembrane domain G protein-coupled receptors, such as CCR2, consist of a single polypeptide chain with an extracellular aminoterminal domain and a cytoplasmic carboxyl-terminal domain. The amino terminal and third extracellular domain have been implicated in receptor-ligand interaction, while the carboxy-terminal and the third intracellular domain cooperate to bind and activate $G$ proteins (Frade et al. 1997). Due to the importance of chemokines in inflammatory processes, special attention has been given to leukocyte receptors that mediate chemokine responses, and the cloning of these receptors has already been reported (Charo et al. 1994).

CCR2 acts as a receptor for MCP1 (Monocytes Chemoattractive Protein type 1), a CC chemokine of the family of chemokines which mediate the chemotaxis of

Send correspondence to Bernardo Galvão-Castro. Laboratório Avançado de Saúde Pública, Centro de Pesquisas Gonçalo Moniz I FIOCRUZ, Rua Waldemar Falcão 121, Brotas, 40.295-001 Salvador, BA, Brazil. E-mail: bgalvao@cpqgm.fiocruz.br. leukocytes. The gene for CCR2 is located at chromosome band 3 p21, and contains three exons distributed over $7 \mathrm{~kb}$ of the genomic sequence (Wong et al. 1997). Two receptors derived from alternative splicing in the carboxyl terminal-coding region of the protein have been identified (CCR2- $\alpha$ and CCR2- $\beta$ ), both of which signal a highly specific response for MCP1 (Charo et al. 1994; Wong et al. 1997).

Like other chemokine receptors (e.g. CCR5, CCR3, and CXCR4), CCR2 plays a role as a co-receptor for HIV-1 infection (Berger et al. 1999; Frade et al. 1997). A nucleotide transition ( $\mathrm{G}$ to $\mathrm{A}$ ) at position 190 of the CCR2 gene was found to produce a substitution of valine to isoleucine in aminoacid 64 of the protein. This represents a conservative change in the protein's first transmembrane domain and, as shown by Smith et al. (1997), does not appear to be a significant risk factor for HIV-1 infection, since infected individuals and highly exposed uninfected individuals do not display significant differences in allelic and genotypic CCR2-64I frequencies. However, progression to AIDS was observed to be two to three years longer in patients who were homozygous or heterozygous for the CCR2-64I mutation, as compared to those with wild-type CCR2 (Smith et 
al. 1997). Subsequent studies investigating the distribution of the CCR2-64I mutation and allelic frequencies in different populations and ethnic groups worldwide (Martinson et al. 2000; Struyf et al. 2000; Mangano et al. 2000; Barbouche et al. 2001; Iyer et al. 2001) have indicated that this mutation is most common in Asian populations (0.250), least common in Europeans (0.098), and of intermediate frequency (0.151) in African populations (Smith et al. 1997). Subsequent studies, however, have shown contradictory values (Struyf et al. 2000).

Here, we investigated the frequency of CCR2-64I in three distinct Brazilian ethnic groups. This is the first work describing the distribution of these mutations in Brazilian HIV- negative populations.

\section{Subjects and Methods}

A total of 655 samples were collected from distinct populations residing in three separate regions of Brazil (North, Northeast, and South); all samples tested negative for HIV-1. The samples from the northeastern region were collected during the epidemiologic evaluation of a basic sanitation program ("Bahia Azul") currently under construction in Salvador, a city with 2.4 million inhabitants (from the Brazilian Demographic Census, IBGE 2000 http://www.ibge.gov.br), $80 \%$ of which are of African descent or mestizos, mainly of mixed Portuguese and African ancestry. The samples from the southern region were collected from 89 German descendents at the Joinville Regional Hemocenter, and the 261 samples from the northern region came from two Indian tribes (179 Tiriyós and 82 Waiampis) which live in a secluded and rugged region along the Brazilian border with French Guyana, in the states of Amapá and Pará. All samples were collected with the informed consent of the participants.

DNA was extracted from both peripheral blood mononuclear cells (PBMCs) and whole blood, using the DNAzol commercial kit (GIBCO-BRL, Rockville, USA). PCR was performed in a Perkin-Elmer 9600 thermal cycler (Perkin-Elmer, Connecticut, USA), using 100 ng of DNA in a final reaction-mixture volume of $25 \mu \mathrm{L}$. Forward with the nucleotide "a" as a mismatch (5'TTGTGGGCAACATGaTGG -3') and reverse (5'GAGCCCACAATGGGAGAGTA - 3 ') primers were used to amplify a $128 \mathrm{bp}$ fragment. The reaction mixture contained 10x PCR buffer at $20 \mathrm{mM}(10 \mathrm{mmol} / \mathrm{L}$ Tris $\mathrm{HCl} \mathrm{pH}$ $8.3,50 \mathrm{mmol} / \mathrm{L} \mathrm{KCl}, 3 \mathrm{mmol} / \mathrm{L} \mathrm{MgCl}_{2}$ and $10 \% \mathrm{BSA}$ ); $1.25 \mathrm{mM}$ of dNTP; $2.5 \mathrm{pmol}$ of each primer, and $2.0 \mathrm{U}$ of Taq DNA polymerase. Thirty-five cycles were performed, each consisting of 1 minute at $72{ }^{\circ} \mathrm{C}, 30 \mathrm{~s}$ at $94^{\circ} \mathrm{C}$, and $30 \mathrm{~s}$ at $59{ }^{\circ} \mathrm{C}$. According to Smith et al. (1997), the amplified products were digested with $5 \mathrm{U} B s a B$ I restriction enzyme for three hours at $60{ }^{\circ} \mathrm{C}$, and electrophoresed on $10 \%$ acrylamide gels. A $128 \mathrm{pb}$ fragment indicated a homozygous wild genotype, while $110 \mathrm{pb}$ and $18 \mathrm{pb}$ fragments di- agnosed the homozygous mutant genotype, and the presence of the three fragments revealed the heterozygous genotype (Figure 1).

\section{Results and Discussion}

The observed allele and genotype frequencies of the CCR2-64I mutation are shown in Table 1. The values obtained are consistent with the Hardy-Weinberg equilibrium.

The homozygous wild-type and heterozygous CCR2-64I genotypes were present in all populations, and the homozygous CCR2-64I genotype was found in all populations except for the one from Joinville. The prevalence of the CCR2-64I mutation in heterozygosis was quite high in all populations studied.

The frequencies found in the indigenous populations are similar to those previously reported in populations of Asian origin (Smith et al. 1997; Su et al. 1999; Voevodin et al. 1999; Mangano et al. 2000; Iyer et al. 2001; Wang et al. 2001; Hong et al. 2001; Ramana et al. 2001). This observation is in accordance with the prevailing theory regarding the Asian origin of Amerindians (Silva et al. 2002), as well as with the theory that CCR2-64I is an ancient mutation, since it is both common in Asians and present in other ethnic groups.

The frequency of the CCR2-64I mutation in the sample from Salvador is consistent with other populations of

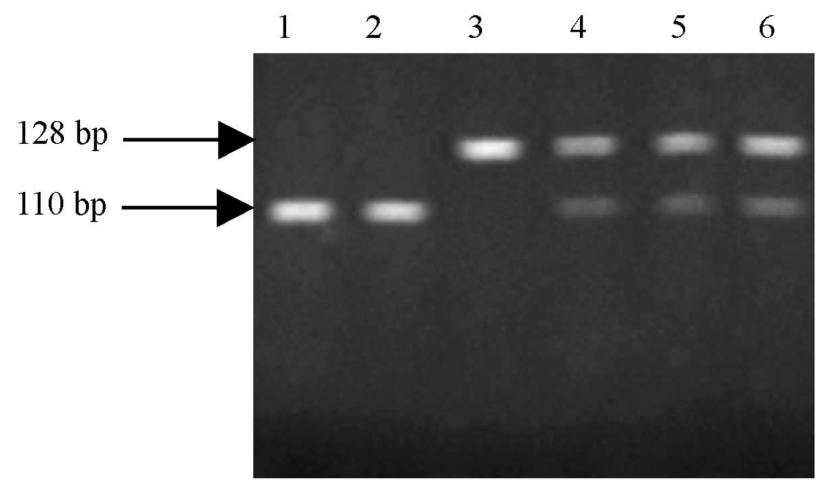

Figure 1 - CCR2-64I mutation genotyping by PCR and $B s a B$ I endonuclease restriction: homozygous CCR2-64I (lanes 1 and 2), homozygous wild-type (lane 3), and heterozygous (lanes 4 to 6) genotypes.

Table 1 - CCR64I allele and genotype frequencies in four Brazilian populations:

\begin{tabular}{lcccc}
\hline Genotypes & \multicolumn{4}{c}{ Populations } \\
\cline { 2 - 5 } & $\begin{array}{c}\text { Salvador } \\
\mathrm{n}=305\end{array}$ & $\begin{array}{c}\text { Joinville } \\
\mathrm{n}=89\end{array}$ & $\begin{array}{c}\text { Tiriyó } \\
\mathrm{n}=179\end{array}$ & $\begin{array}{c}\text { Waiampi } \\
\mathrm{n}=82\end{array}$ \\
\hline $\mathrm{wt} / \mathrm{wt}$ & $227(74 \%)$ & $57(64 \%)$ & $92(51 \%)$ & $39(48 \%)$ \\
$\mathrm{wt} / 64 \mathrm{I}$ & $73(24 \%)$ & $32(36 \%)$ & $80(45 \%)$ & $37(45 \%)$ \\
64I/64I & $5(2 \%)$ & $0(0 \%)$ & $7(4 \%)$ & $6(7 \%)$ \\
CCR2-64I allele & 0.14 & 0.18 & 0.26 & 0.30 \\
\hline
\end{tabular}


predominantly African origin (Smith et al. 1997; Martinson et al.2000, Iyer et al. 2001), reflecting the widespread African/European miscegenation in this population.

Although the individuals from Joinville were considered as being of European descent, the observed mutant allele and genotype frequencies were much higher than those found in European populations. This is apparently due to the fact that, although this population descended primarily from Europeans, considerable miscegenation has probably occurred after the original German migrations to Brazil. A high frequency of CCR2-64I (14.37\%) has also been observed in European-derived populations of other countries (Iyer et al. 2001).

The prevalence of mutations that influence AIDS pathology and progression is relevant for the establishment of strategies for the prevention and treatment of AIDS, and, as shown for the CCR64I mutation, they should be investigated in different populations, taking into account their ethnic background and genetic diversity.

\section{Acknowledgements}

The authors are grateful to Dr. Marc Van Ranst for providing the control samples (heterozygous and homozygous CCR2-64I genotypes) that were imperative for accurate genotyping. This work was partially supported by Programa de Apoio à Pesquisa Estratégica em Saúde (PAPES).

\section{References}

Berger EA, Murphy PM and Farber JM (1999) Chemokine receptors as HIV-1 co-receptors: roles in viral entry, tropism, and disease. Annu Rev Immunol 17:657-700.

Barbouche RM, Hong L, Dellagi K and Kostrikis LG (2001) Contrasting frequencies of CCR5delta32 and CCR2-64I alleles in the Tunisian population. J Acquir Immune Defic Syndr 26:298-299.

Charo IF, Myers SJ, Herman A, Franci C, Connolly AJ and Coughlin SR (1994) Molecular cloning and functional expression of two monocyte chemoattractant protein 1 receptors reveals alternative splicing of the carboxyl-terminal tails. Proc Natl Acad Sci USA 91:2752-2756.

Frade JM, Llorente M, Mellado M, Alcami J, Gutierrez-Ramos JC, Zaballos A, Real G and Martinez AC (1997) The amino-terminal domain of the CCR2 chemokine receptor acts as coreceptor for HIV-1 infection. J Clin Invest 100:497-502

Hong W, Wang F, Jin L, Xing L, Liu M, Du Q, Lei Z and Li J (2001) Genotyping of HIV resistant alleles in indigenous Tibetan ethnic group of China: low frequency of CCR $5 \Delta 32$ and high frequency of CCR2b-64I alleles. Zhonghua Yi Xue Yi Chuan Xue Za Zhi 18:268-271.

Iyer RK, Kim PS, Bando JM, Lu KV, Gregg JP and Grody WW (2001) A multiethnic study of Delta32ccr5 and ccr2b-V64I allele distribution in four Los Angeles populations. Diagn Mol Pathol 10:105-110.

Mangano A, Kopka J, Batalla M, Bologna R and Sen L (2000) Protective effect of CCR2-64I and not of CCR5-delta32 and SDF1-3'A in pediatric HIV-1 infection. J Acquir Immune Defic Syndr 23:52-57.

Martinson JJ, Hong L, Karanicolas R, Moore JP and Kostrikis LG (2000) Global distribution of the CCR2-64I/CCR5-59653T HIV-1 disease-protective haplotype. AIDS 14:483-489.

Ramana GV, Vasanthi A, Khaja M, Su B, Govindaiah V, Jin L, Singh L and Chakraborty R (2001) Distribution of HIV-1 resistance-conferring polymorphic alleles SDF-1-3'A, CCR2-64I and CCR5-Delta32 in diverse populations of Andhra Pradesh, South India J Genet 80:137-140.

Silva WA Jr, Bonatto SL, Holanda AJ, Ribeiro-dos-Santos AK, Paixao BM, Goldman GH, Abe-Sandes K, RodriguezDelfin L, Barbosa M, Paco-Larson ML, Petzl-Erler ML, Valente V, Santos SE and Zago MA (2002) Mitochondrial genome diversity of Native Americans supports a single early entry of founder populations into America. Am J Hum Genet 71:187-192.

Smith MW, Dean M, Carrington M, Winkler C, Huttley GA, Lomb DA, Goedert JJ, O-Brien TR, Jacobson LP, Kaslow R, Buchbinder S, Vittinghoff E, Vlahov D, Hoots K, Hilgartner MW and O-Brien SJ (1997) Contrasting genetic influence of CCR2 and CCR5 variants on HIV-1 infection and disease progression Hemophilia Growth and Development Study (HGDS), Multicenter AIDS Cohort Study (MACS), Multicenter Hemophilia Cohort Study (MHCS), San Francisco City Cohort (SFCC), ALIVE Study. Science 277:959-965.

Struyf F, Thoelen I, Charlier N, Keyaerts E, Van der Donck I, Wuu J and Van Ranst M (2000) Prevalence of CCR5 and CCR2 HIV-coreceptor gene polymorphisms in Belgium. Hum Hered 50(5):304-307.

Su B, Jin L, Hu F, Xiao J, Luo J, Lu D, Zhang W, Chu J, Du R, Geng Z, Qiu X, Xue J, Tan J, O-Brien SJ and Chakraborty R (1999) Distribution of two HIV-1-resistant polymorphisms (SDF1-3'A and CCR2-64I) in East Asian and world populations and its implication in AIDS epidemiology. Am J Hum Genet 65(4):1047-1053.

Voevodin A, Samilchuk E and Dashti S (1999) Frequencies of SDF-1 chemokine, CCR-5, and CCR-2 chemokine receptor gene alleles conferring resistance to human immunodeficiency virus type 1 and AIDS in Kuwaitis. J Med Virol 58:54-58.

Wang F, Jin L, Lei Z, Shi H, Hong W, Xu D, Jiang J, Wang Y, Zhang B, Liu M and Li Y (2001) Genotypes and polymorphisms of mutant CCR5-delta 32, CCR2-64I and SDF1-3' a HIV-1 resistance alleles in indigenous Han Chinese. Chin Med J 114:1162-1166.

Wong LM, Myers SJ, Tsou CL, Gosling J, Arai H and Charo IF (1997) Organization and differential expression of the human monocyte chemoattractant protein 1 receptor gene. Evidence for the role of the carboxyl-terminal tail in receptor trafficking. J Biol Chem 10:1038-1045.

Editor: Francisco Mauro Salzano 